\title{
Review: double bag or Y-set systems reduce peritonitis in patients on continuous ambulatory peritoneal dialysis
}

Daly C, Campbell M, Cody J, et al. Double bag or Y-set versus standard transfer systems for continuous ambulatory peritoneal dialysis in end-stage renal disease. Cochrane Database Syst Rev 2001;(2):CD003078 (latest version 28 Feb 2001).

\section{QUESTION: Do double bag and Y-set exchange systems reduce peritonitis in patients receiving continuous ambulatory peritoneal dialysis (CAPD) compared with standard systems?}

\section{Data sources}

Randomised and quasi-randomised trials in any language were identified by searching Medline (1966 to September 1999), EMBASE/Excerpta Medica (1984 to October 1999), CINAHL (1982-96), BIOSIS (1985-96), Cochrane Library, SIGLE (1980 to June 1996), and National Research Register ( $14^{\text {th }}$ consolidation September 1996); hand searching Kidney International (198097); reviewing bibliographies of studies and relevant book chapters; and contacting authors and relevant biomedical companies.

\section{Study selection}

Studies were selected if they included patients with end stage renal disease who were treated or expected to be treated with CAPD, and if they compared double bag and/or Y-set exchange systems with standard CAPD exchange systems or compared double bag with Y-set systems.

Source of funding: NHS Executive Research and Development Programme UK.

For correspondence: Dr C Daly, Department of Medicine and Therapeutics, University of Aberdeen, Polwarth Building, Foresterhill, Aberdeen $A B 252 Z D$, UK. Fax $+44(0) 122$ 4699884.
Comparison of exchange systems for reducing peritonitis in patients on continuous ambulatory peritoneal dialysis*

\begin{tabular}{llll} 
Comparison & $\begin{array}{l}\text { Weighted } \\
\text { event rates RRR }(95 \% \mathrm{Cl})\end{array}$ & NNT (CI) \\
$\begin{array}{l}\text { Double bag or } \\
\text { Y-set } v \text { standard }\end{array}$ & $33 \% v 60 \%$ & $44 \%(33$ to 53$)$ & $4(3$ to 6$)$ \\
\hline $\begin{array}{l}\text { Double bag } v \\
\text { Y-set }\end{array}$ & $30 \% v 49 \%$ & $40 \%(19$ to 56$)$ & $6(4$ to 12$)$ \\
\hline${ }^{*}$ Abbreviations defined in glossary; RRR, NNT, and $\mathrm{Cl}$ calculated from data in
\end{tabular}

article. Mean duration of follow up not provided.

\section{Data extraction}

Data were extracted on study methods (allocation concealment, blinding, description of withdrawals and dropouts, duration of follow up, and whether intention to treat analysis was used), patients, interventions, and outcomes. Main outcome of interest was peritonitis. Secondary outcomes included exit site infections, switch to haemodialysis, and mortality.

\section{Main results}

12 trials ( $\mathrm{n}=991)$ met the inclusion criteria. Meta-analysis showed that fewer patients using double bag or Y-set systems had peritonitis than those using standard systems ( 8 trials, $\mathrm{n}=626$ ) (table). The double bag and Y-set systems did not differ from standard systems for exit site infections (3 trials, $\mathrm{n}=264$ ), number switching to haemodialysis ( 3 trials, $\mathrm{n}=264$ ), or mortality (6 trials, $\mathrm{n}=435$ ).

Comparison of the double bag and Y-set systems showed that fewer patients using the double bag system had peritonitis ( 3 trials, $n=292$ ) (table). The double bag and Y-set systems did not differ for number switching to haemodialysis (2 trials, $\mathrm{n}=145$ ) or mortality (2 trials, $\mathrm{n}=193)$.

\section{Conclusions}

Double bag and Y-set systems, compared with standard exchange systems, reduce peritonitis in patients with end stage renal disease who are on continuous ambulatory peritoneal dialysis. Double bag systems have an

\section{COMMENTARY}

This systematic review by Daly $e t$ al is thorough in its identification of studies, extraction and analysis of data, and presentation of findings. It draws on data from 12 randomised (or quasi-randomised) trials and provides high quality evidence to support what nephrology nurses already know - that CAPD using Y-sets, especially double bag systems, reduces the incidence of peritonitis. There remain, however, some difficulties with interpreting some of the secondary outcomes contained within the full review. These include problems of definition (eg, technique failure could mean changing to haemodialysis, different dialysate transfer set, or stopping dialysis altogether), lack of data (eg, on catheter removal and admission to hospital), and problems with validity of study tools (eg, those used to measure quality of life).

CAPD is widely regarded, in Canada and the UK, as the treatment of choice for patients with end stage renal disease who wish to take control of their own treatment. It is estimated that >105 000 individuals are on peritoneal dialysis worldwide, which is about $15 \%$ of the global dialysis population. ${ }^{1}$ Although it appears that the incidence of peritonitis and associated rates of admission to hospital are decreasing, ${ }^{2}$ peritonitis remains the most important challenge facing peritoneal dialysis nurses. The Renal Association in the UK recommends that disconnect systems such as Y-set or double bag systems "should be standard for all patients" unless they are incapable of mastering the technique. ${ }^{3}$ When compared with the human and financial costs of treating peritonitis, the minimal increase in cost incurred using disconnect systems is wholly justified, making them the only viable option for providing CAPD in the 21 st century.

Peter A Ellis, RN, MSc, MA Research Projects Manager The Renal Unit, King's College Hospital London, UK

1 Gokal R. Long-term CAPD therapy. Br J Renal Med 1998;3:20-2.

2 Fried L, Abidi S, Bernardini J, et al. Hospitalisation in peritoneal dialysis patients. Am J Kidney Dis 1999;33:927-33.

3 Renal Association, Standards Subcommittee, Royal College of Physicians of London. Treatment of adult patients with renal failure: recommended standards and audit measures. London, UK: Renal Association, 1995. 